\title{
Three-dimensional unsteady energy simulation of building envelopes composed of hollow concrete blocks
}

\author{
Gustavo Cherem-Pereira ${ }^{1, *}$, Nathan Mendes $^{2}$, and Walter Mazuroski ${ }^{3}$ \\ 1,2,3Pontifical Catholic University of do Paraná (PUCPR), Mechanical Engineering, Brazil
}

\begin{abstract}
Building Energy Simulation (BES) tools commonly use 1-D formulation for computing conductions loads through building envelopes. As this assumption may cause significant errors on the prediction of building energy and thermal performance, this work proposes a methodology for taking into account the 3-D heat transfer phenomenon nature and compare the results for three case studies. The different approach is also used to investigate the effects of considering brick's cavity detailing with convection and radiation phenomena on the results of transient simulations at the building scale. The present method has the potential to increase precision in the energy analysis of buildings and analyse more precisely the performance of elements of complex geometry. The results demonstrate that traditional simulation methods may not ensure good precision. The magnitude of relative errors varies significantly in each case study.
\end{abstract}

\section{Introduction}

As buildings are highly energy consumers [1], building energy simulation tools have been developed since the seventies aiming at improving their energy efficiency. Many tools have been reported in [2-4] and several research work focusing on energy efficiency of building envelopes can be found in the literature as in [5-13]. Wall parameters such as thermal resistance and thermal inertia are commonly investigated such as in [4-6] or thermal conductivity in [7]. Many studies are also focused on determining the optimum insulation thickness of different wall configurations [8-13]. Nevertheless, most of BES tools use purely diffusive 1-D formulation, including walls built with elements that have cavities. The purely diffusive 1-D formulation neglects important phenomena relating to heat transfer and fluid mechanics. Heat transfer phenomena that occur inside cavities are erroneously simplified. The present study investigates errors this assumption causes by developing a cosimulation using a BES and a CFD program, and comparing the results of three case studies.

The main objective of the present work is to investigate the effects of considering cavity detailing with correct mass distribution, convection and radiation phenomena in the interior of walls on the results of transient simulations of the building scale. The methodology presented has the potential to increase precision in energy analysis of buildings and analysing the performance of constructive elements.

To achieve the objectives, three case studies are configured, with an increasing degree of complexity in both the construction of the wall and the boundary conditions, from a model of two superimposed blocks to a ventilated wall model with short wave radiation asymmetry, as detailed in the methodology section. The simulations are transient, at the scale of a building, by means of two simulation methods: i) Traditional, 1-D, purely diffusive method where the layer containing elements with cavities is represented by three equivalent thermal properties; and ii) New 3-D co-simulation method using BES and CFD programs where the elements are physically modelled in more detail.

The coupling of the two programs provides a refined and more realistic three-dimensional analysis of the phenomena inside the wall. The development of the cosimulation method using the BES and CFD programs was part of the present work.

In a different way, the present work uses the coupling between the two programs to detail the interior of the wall. However, there have been developmental and experimental validations of coupling methodologies between these two types of formulations since 1998, such as Negrão [14], Zhai and Chen [15, 16, 17 and 18], Bartak et al. [19], Djunaedy et al. [20] and Wang and Wong [21]. The coupling between these two types of software is interesting because they complement each other.

\section{Methodology}

\subsection{Co-simulation}

Transient simulations in both softwares occur simultaneously over the same period for calculating heat transfers through the wall and energy balances in the environment. BES (Domus) has a dynamic model for the

\footnotetext{
* Corresponding author: gustavocherem@gmail.com
} 
analysis of building energy performance. The heat transfer on each wall is calculated by finite differences in 1-D analysis; however, in the coupled method, the threedimensional velocity and temperature fields are calculated at each time step by the CFD software (Ansys-CFX).

Given the boundary conditions, the BES starts the transient trajectory transferring them to the CFD with each BES time step, where it is usually taken as 5 to 30 mins. The CFD then initiates the first transient simulation within the selected period that coincides with the BES time step.

In the simulations performed in this work, the BES time step will be 20 mins. The time step chosen in the CFD for the transient simulation inside the wall is $1 \mathrm{~min}$. The CFD output file informs the average internal surface temperature of the internal plaster, which is then used by BES to perform a new energy balance in the environment. BES, in turn, updates the CCL file of the CFD Setup with updated indoor and outdoor boundary conditions and a new transient period of 20 mins starts. The cycle repeats to convergence. The convergence check is performed by comparing the results at each time step of the previous day and considering the convergence reached where the results are unchanged, less than residue. Before each transient trajectory of $20 \mathrm{~min}$, a steady-state simulation is performed in the CFD to update the internal air velocity field into the cavities. This process of freezing the air velocity field, every 20 min inside the cavities, minimizes the processing time and maintains the precision of the results according to the study presented in [22]. The residue used for convergence of the transient simulation in the CFD is of 1E-4 for Cases \#1 and \#2 and 1.5E-4 for Case \#3, determined from the study presented in [22]. The Python computational language is used for the data exchange files, according to Ansys.

\subsection{Case Studies}

The three cases use the standard test environment illustrated in Figure 1, which shows the top view of the environment where black filled walls are adiabatic. Only on the wall under analysis heat transfer occurs. This environment adopts the same internal dimensions of the BESTEST environment [23]. For all three cases, the internal temperature of the environment is fixed. In Case $\# 1$, this is $24^{\circ} \mathrm{C}$; and in other cases, it is $20^{\circ} \mathrm{C}$, simulating a perfect control. The external boundary conditions of each case are described below. For all three cases, the same settings apply to both simulation methods for the comparison of the results.

The CFD domains are a pile of blocks. In Case \#1 are 2 blocks. Other cases are 14 blocks. The four side faces are adiabatic and the interior of wall is completely modelled to transfer heat from indoor to outdoor or the opposite.

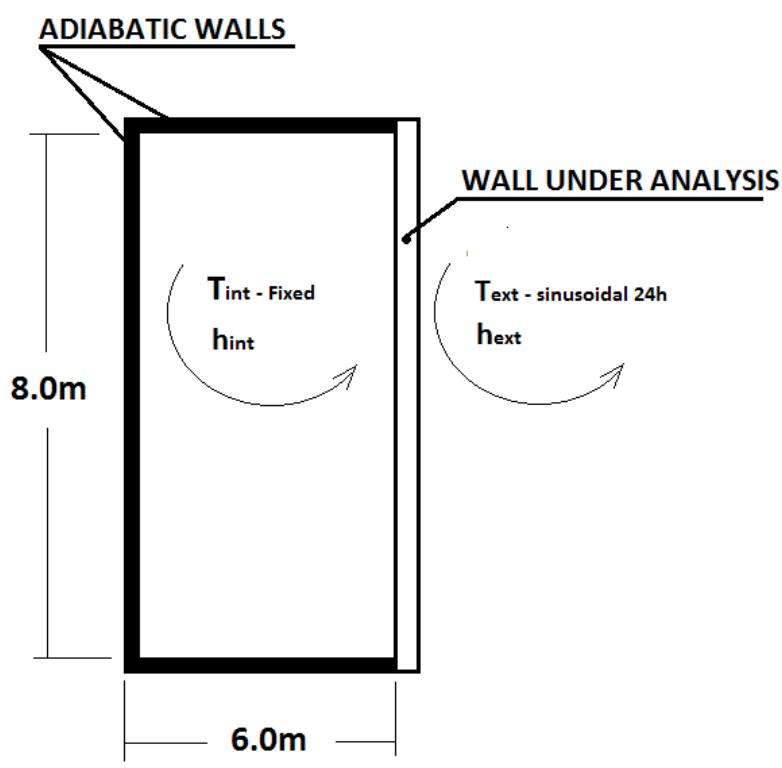

Fig. 1. Room.

\subsubsection{Case of study \#1}

The outdoor temperature varies sinusoidally with a period of one day. The chosen sinusoidal function represents the winter temperatures of the southern Brazilian region. The external surface of the wall under analysis receives radiation, which includes direct and diffuse radiation. The radiation has variable magnitude starting from $0 \mathrm{~W}$ at 7:00AM, peaking at $498 \mathrm{~W}$ at noon and returning at $0 \mathrm{~W}$ at 6:00PM. In this way, the boundary conditions take on the natural behaviour of a day. Therefore, there is a cold night and a sunny day, causing inward and outward heat fluxes.

The wall in analysis is constructed with concrete blocks of dimensions of 390 (L) x 190 (W) x 140 mm $(\mathrm{H})$, assembled with mortar and containing plaster in both sides, as shown in Figure 2. It shows the enhanced concrete block studied by [22]. Two concrete blocks are used in the CFD assembling and the results found are considered for the entire wall.

To evaluate the performance among different simulation methods the results bellow will compare the average of inner surface temperature $\left[\mathrm{T}_{\text {surfin }}\right]$ of the wall under analysis. This temperature will be used by BES to calculate the amount of heat entered in the room each time step.

\subsubsection{Case of study \#2}

In this case, the wall has its height modelled in the CFD, with 14 concrete blocks, also assembled with mortar and containing plaster in both indoor and outdoor environments. Both cases \#2 and \#3 the modelling considers that there are no bad finishes that partially close the column of cavities. In width, the domain is represented by the width of a single block of concrete. At the upper end of the wall, at the height of the ceiling, an overhang is considered, such that solar radiation, 
according to the time of day, strikes totally or partially on, or does not reach, the wall. The objective is to highlight the importance of detailed modelling of the interior of the wall, however, here adding effects from the Sun in a heating up of the lower portion of the wall. The air that fills the cavities will be heated from below and its convective movement makes it possible to preheat the above blocks still under shade. Figure 3 illustrates the case, showing the environment in lateral and cut view, where the wall under analysis has solar radiation incidence. The movement of the sun is downward in all simulations due to the orientation of the wall to the west, primarily heating its bottom region.

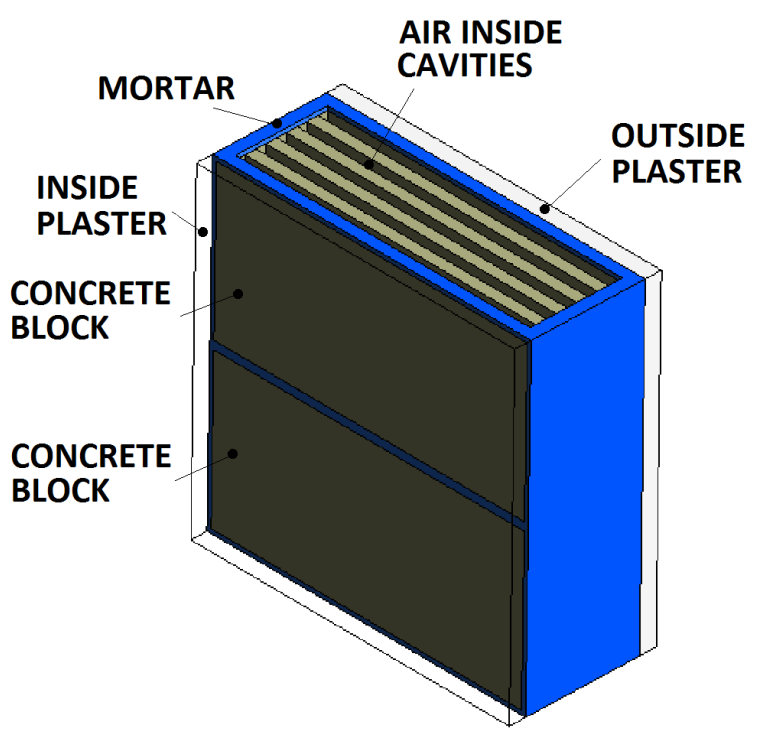

Fig. 2. Simulated domains in Case \#1.

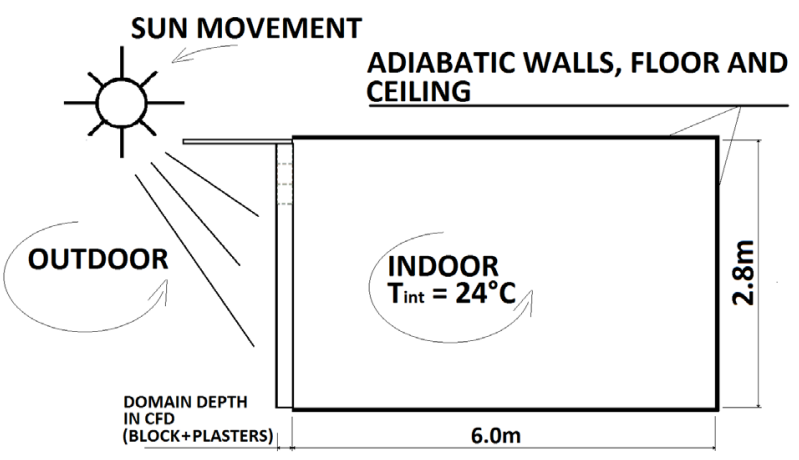

Fig. 3. Illustration of Case \#2.

This procedure becomes possible in the coupling, even for very complex geometries, thanks to the pixel counting techniques implemented in Domus [24]. Domus also provides the boundary conditions base on hourly weather data files.

In case \#2 the wall under analysis is also composed of concrete blocks of dimensions of 390 (L) x 190 (W) x $140 \mathrm{~mm}(\mathrm{H})$ - largely used in Brazil, assembled with mortar and containing plaster in both sides. Figure 5 illustrates the concrete blocks assembled.

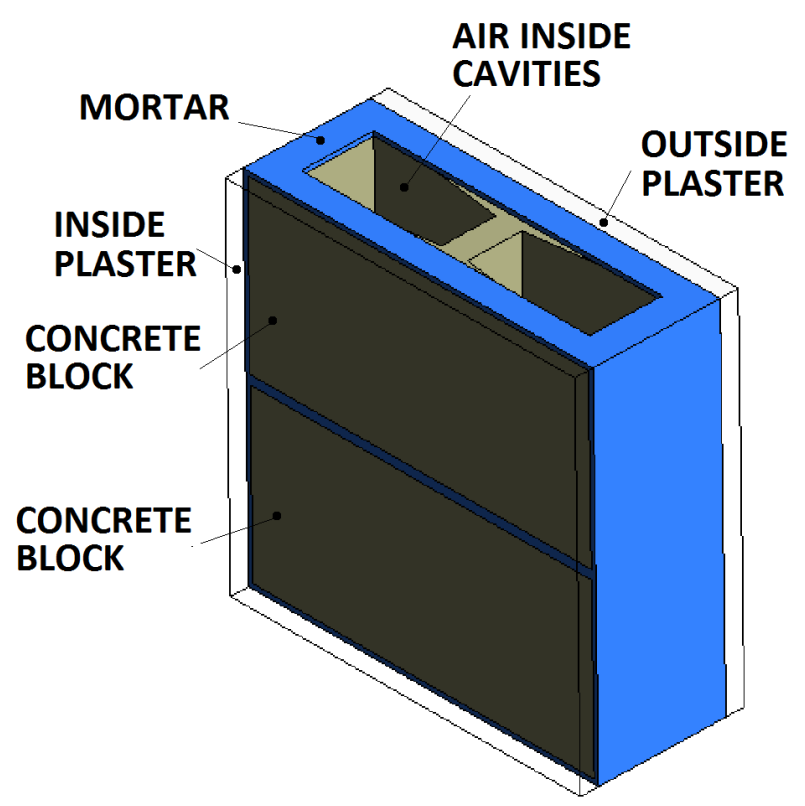

Fig. 5. Concrete Block used in Case \#2.

\subsubsection{Case of study \#3}

In case \#3, the wall under analysis gains a layer of ventilated air, $5 \mathrm{~cm}$ in thickness, as shown in Figure 6, constructed with ceramic plates in the external face of the wall. The lower and upper entrances of the ventilated air layer are $10 \mathrm{~cm}$ high and provide freedom for air from the ventilated layer to leave to the external environment or air from the external environment to enter the layer. For this case, the relative pressure between the internal domain of the ventilated air layer and the external air is $0 \mathrm{~Pa}$. In this way, it is considered that the wind is not interfering with the ventilation of the air layer.

The ventilated façade is an industrialized constructional system in which a mechanical system is used to fix the coating plates. Its function is to create a protection against moisture and mildew and atmospheric agents, and to promote thermal insulation.

Therefore, in this case, the potential of the BES CFD integration is explored in greater depth with enrichment of details in the model.

The overhang is present, at the height of the ceiling, as in the last case. The ceramic plates will be heated by solar radiation starting at $2 \mathrm{pm}$ in the lower portion. At 6 $\mathrm{pm}$, the solar radiation reaches $100 \%$ of the wall area. Figure 8 illustrates the case, showing the environment on the side and cut view. In case \#3, the wall under analysis is constructed with concrete blocks shown in Figure 3, having dimensions 390 (L) x 190 (W) x 140 mm (H). It is also assembled with mortar and contains plaster in both indoor and outdoor environments. The domain of CFD simulation has 14 blocks in height. 


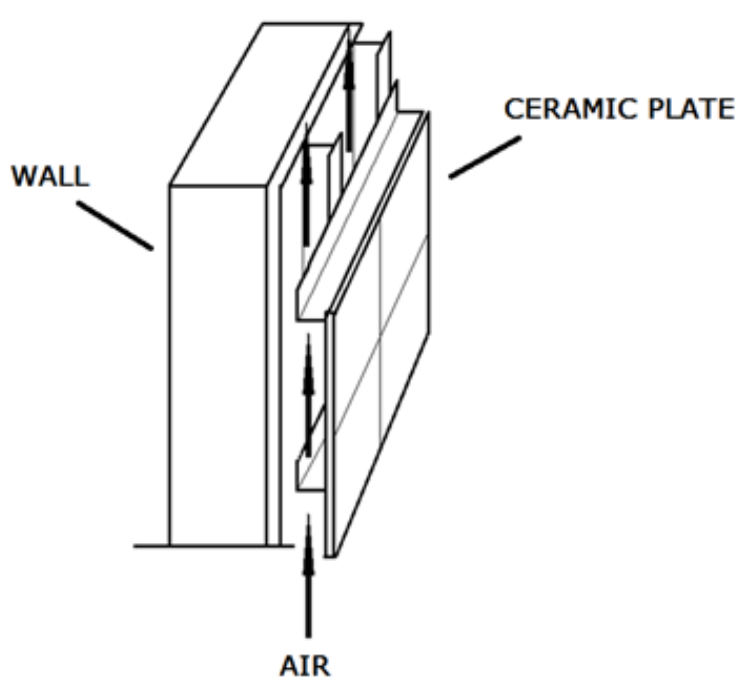

Fig. 6. Assembling of ventilated air layer.

\section{Results}

The results found for the three case studies are presented next. The graphs of the results show the root mean square (RMS) error of the simulations performed on Domus in relation to the simulations performed with the coupling, where their results are considered closer to real values.

For the simulations with the traditional method of BES software, one could classify three kind of users to investigate the different error levels regarding simulation of buildings composed by hollowed elements:

i) Basic User: this user employs the data from the software library or Internet and literature sources to choose equivalent thermo-physical properties of each material or element, for instance, the equivalent thermal conductivity of the concrete block.

ii) Professional User: this user calculates the equivalent properties of the building elements according to existing standards, for instance, [25] and [26].

iii) Advanced User: the highly specialized one who uses a CFD model to calculate the equivalent properties.

Each user class above will obtain different results owing to the precautions taken to obtain the properties.

\subsection{Results found in CASE \#1}

Figure 7 presents the mean temperature results for the inner surface of the wall throughout the simulated day for both simulation methods. For the coupled method, during the late night and early morning, the mean temperature at the inner surface of the wall is higher than the mean value found by the BES simulation. In these periods the external surface temperature is lower than that of the inner surface, therefore, the detailing of the inside of the wall increases the overall thermal resistance. After $10 \mathrm{am}$, when the temperature of the external surface increases, becoming higher than the mean temperature of the inner surface, it presents lower values in the coupled simulation, exhibiting better thermal insulation with the BES-CFD co-simulation. The temperature differences are important, reaching $0.59^{\circ} \mathrm{C}$ at 8:20 am. The averaged RMS mean difference is $0.36^{\circ} \mathrm{C}$.

Figure 7 also presents the results obtained by a professional user who added to the BES the equivalent thermal conductivity value calculated by the method indicated in the standard [26], $0.304 \mathrm{~W}(\mathrm{mK})-1$. The results obtained by this user are very different from those of the advanced user, a fact that will be demonstrated by the calculations of the integration of the energy transferred in $24 \mathrm{~h}$ of Table 2.

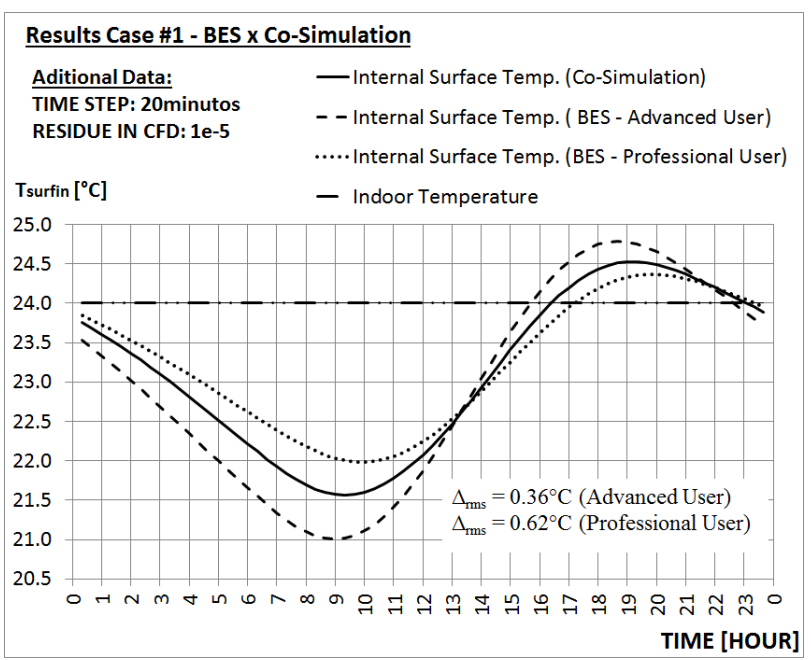

Fig. 7. Results Case \#1: mean inner surface temperature.

Figure 8 presents the heat flux values in the analysed wall for both simulation methods. The heat transfer rates range from $-26.1 \mathrm{~W} / \mathrm{m}^{2}$ to $6.9 \mathrm{~W} / \mathrm{m}^{2}$. The instantaneous differences reach values up to $5.2 \mathrm{~W} / \mathrm{m}^{2}$.

Table 1 indicates the integration of the daily transferred energy in $\mathrm{kJ}$. The difference is $11.7 \%$ of heat transferred to the outdoors, and the heat transferred indoors was reduced by $29.8 \%$. These are expressive differences that affect the calculations of the energy consumption of air conditioning equipment and the verifications of whether the building energy ratings are met.

The concrete block that was used has five cavities, with the two closest to the indoor and outdoor surfaces presenting more intense convection activities in relation to the others. This allows for differing the thermal resistances of each cavity and valuing the internal detailing of the concrete block in the simulation, which cannot be done with the 1-D simulation common to the BES software.

It is important to observe that the present study evaluates the difference of detailing the inside of the wall, comparing it to the BES, having the exact equivalent properties, calculated by CFD itself with the same model used in the coupling (advanced user). Therefore, detailing the inside of the wall using the coupling method guarantees precise results. In turn, the 
BES method depends on the equivalent properties informed by the user. If this information contains errors, the simulations will be inaccurate, which can be observed in the results obtained by the professional and basic users.

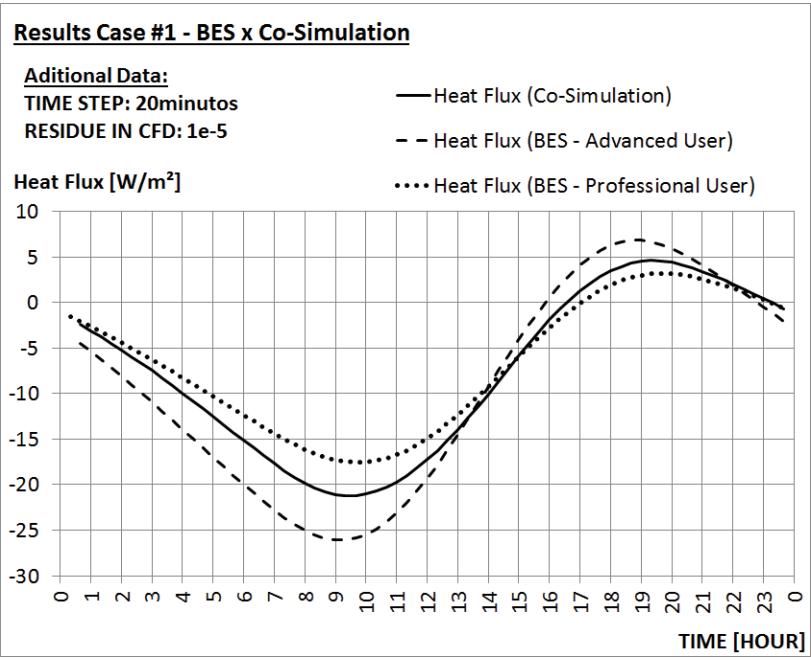

Fig. 8. Results Case \#1: heat flux at the internal surface.

Table 1. Case \#1 - Quantity of exchanged energy for both simulation methods - Traditional vs. Co-simulation.

\begin{tabular}{|c|c|c|}
\hline Energy & $\begin{array}{c}\mathrm{E}_{\mathrm{T}_{\_} \text {out }} \\
(\mathrm{kJ})\end{array}$ & $\begin{array}{c}\mathrm{E}_{\mathrm{T} \_ \text {in }} \\
(\mathrm{kJ})\end{array}$ \\
\hline Professional BES User (1) & $-13,399$ & 986 \\
\hline Advanced BES User (2) & $-19,203$ & 2,326 \\
\hline Co-simulation BES-CFD (3) & $-16,947$ & 1,633 \\
\hline Difference (\%) (1 -3) & 26.5 & 66 \\
\hline Difference (\%) (2 -3) & -12 & -30 \\
\hline
\end{tabular}

\subsection{Results found in CASE \#2}

The results are presented in Figure 9, in terms of the mean temperature of the inner surface of the wall. As observed, the behavior of the temperature on the inner surface of the wall varies a lot between simulations and the gain in the precision of results is very high with cosimulation. The surface temperatures at night are different, by approximately $0.35^{\circ} \mathrm{C}$. During the day, the error levels are higher, reaching $2.15^{\circ} \mathrm{C}$ in the afternoon, when the asymmetry of the short-wave radiation boundary condition is more accentuated. The averageds RMS value is $1.0^{\circ} \mathrm{C}$ for the traditional simulation.

Figure 9 also plots the results obtained by the basic user who applied the same concrete block from the Domus library, with the same dimensions. As the equivalent thermal conductivity of the block from the Domus library is lower, $0.461 \mathrm{~W}(\mathrm{mK})-1$, the inner surface temperatures remain lower, approaching the results for the coupling during the period of solar incidence on the wall. In any case, the error values remained high when compared to the coupled simulation. Differences in the surface temperatures differences are maintained throughout the day, ranging from $0.1^{\circ} \mathrm{C}$ to $1.6^{\circ} \mathrm{C}$.

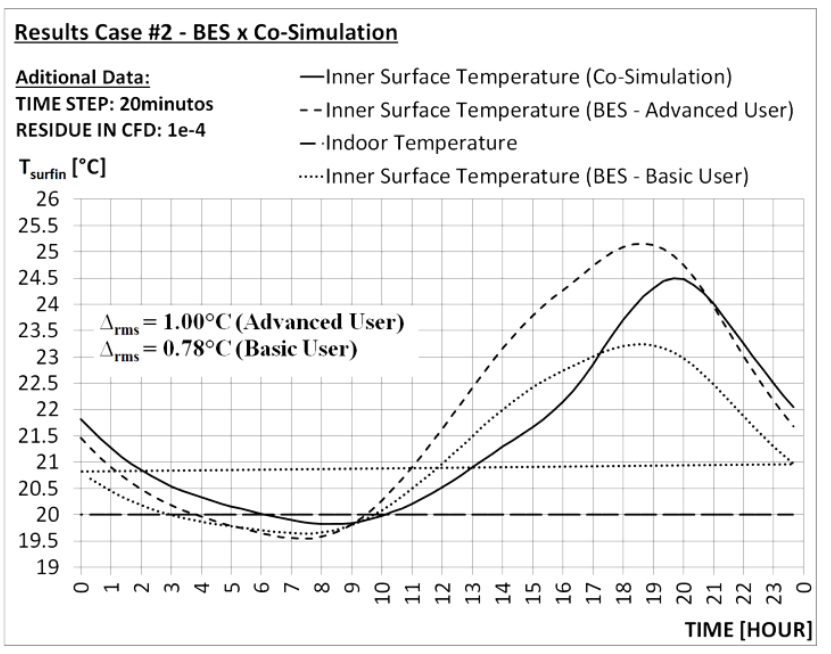

Fig. 9. Results Case \#2: mean inner surface temperature.

These temperature differences might seem small, but they cause great differences in the heat flux. Table 2 shows the integrated energy in 24 hours. The large heat exchange flows towards the environment, where it is reduced by $24.1 \%$ with the coupling methodology.

The heat flux results for the basic user are also calculated. However, the basic users obtained high error levels, a $25.4 \%$ difference in the integrated heat entering the environment, compromising their results.

Table 2. Case \#2 - Quantity of exchanged energy for both simulation methods - Traditional vs. Co-simulation.

\begin{tabular}{|c|c|c|}
\hline Energy & $\begin{array}{c}\mathrm{E}_{\mathrm{T}_{\_} \text {out }} \\
(\mathrm{kJ})\end{array}$ & $\mathrm{E}_{\mathrm{T}_{-} \text {in }}(\mathrm{kJ})$ \\
\hline Basic BES User (1) & -198 & 20,346 \\
\hline Advanced BES User (2) & $-1,142$ & 33,616 \\
\hline Co-simulation BES-CFD (3) & -323 & 25,513 \\
\hline Difference (\%) (1 -3) & 63 & 25 \\
\hline Difference (\%) (2 -3) & -72 & -24 \\
\hline
\end{tabular}

Figure 10 shows the hourly temperature fields inside the analyzed wall from $1 \mathrm{pm}$ to $6 \mathrm{pm}$. As expected, when observing the air inside the cavities of the concrete blocks, the air that would be heated in the lower section of the wall already heated by the sunrays will heat the upper section that is still shadowed. This effect is shown in all figures from $2 \mathrm{pm}$ to $6 \mathrm{pm}$.

In turn, at $2 \mathrm{pm}$, the air from the cavities of the three upper concrete blocks is hotter than the air in the central blocks. The three-dimensionality offered by the coupled modelling method inside the wall allows this. The temperature of these blocks is higher, and the results are more precise, as the simulation is closer to reality.

In the temperature profiles of the following times, 3 pm- $6 \mathrm{pm}$, it is clear that the air is being heated by hot 
regions and then it is transferring heat to other regions. The velocity fields with vectors not showed in paper, also details the ascending vectors transferring heat to the upper blocks by convection.

The total processing time of the reported simulation was $798 \mathrm{~h}$. Computer data: Intel Core I5 processor, four $2.30 \mathrm{GHz}$ processors, $6.0 \mathrm{~GB}$ memory.

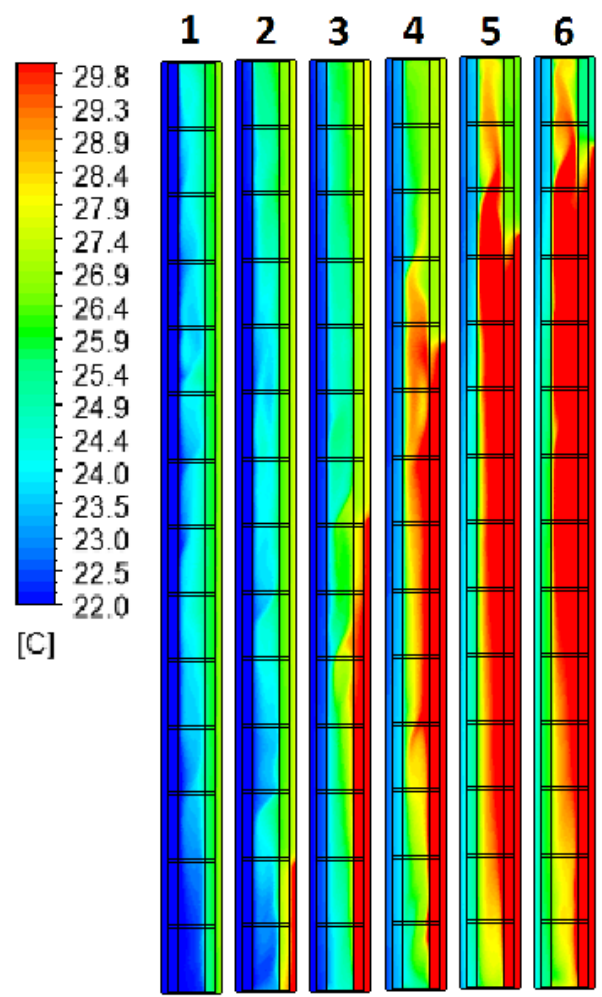

Fig. 10. Temperature fields from 1:00 p.m. to 6:00 p.m. - Case \#2.

\subsection{Results found in CASE \#3}

Case \#3 includes a ventilated air cavity in the wall, which fills the space between the outside plaster, applied on the concrete block, and ceramic boards. Figure 11 shows the domains simulated in the CFD. The total processing time in this case was $840 \mathrm{~h}$. Computer data: Intel Core I5 processor, four $2.30 \mathrm{GHz}$ processors, 6.0 GB memory.

In this Case, the results found with the 3-D approach have even more differences in relation to the traditional method. Figure 12 shows the results for the mean temperature of the inner surface of the analysed wall, maintaining the results of Case \#2 in the graph.

The thermal insulation of the wall is greater in the BESCFD coupled method. Throughout the $24 \mathrm{~h}$ period, the temperature of the inner surface of the wall remains very close to the temperature of the living room, $20^{\circ} \mathrm{C}$, reaching a maximum value of $20.26^{\circ} \mathrm{C}$. In turn, in the simulation performed with the BES method, the temperature of the inner surface of the wall presents larger variations, especially in the afternoon period, when there is direct solar radiation, reaching $22.42^{\circ} \mathrm{C}$.

Nevertheless, the heat exchanged between the wall and the environment corroborates the observed differences. Figure 13 presents the heat flux variation through the wall for both simulation methods throughout the day. The heat fluxes are less intense on the wall when simulated with the highest detailing level offered by the coupling. When the heat transfer rate through the wall throughout the day is integrated, as shown in Table 3 , the difference reaches $88 \%$.
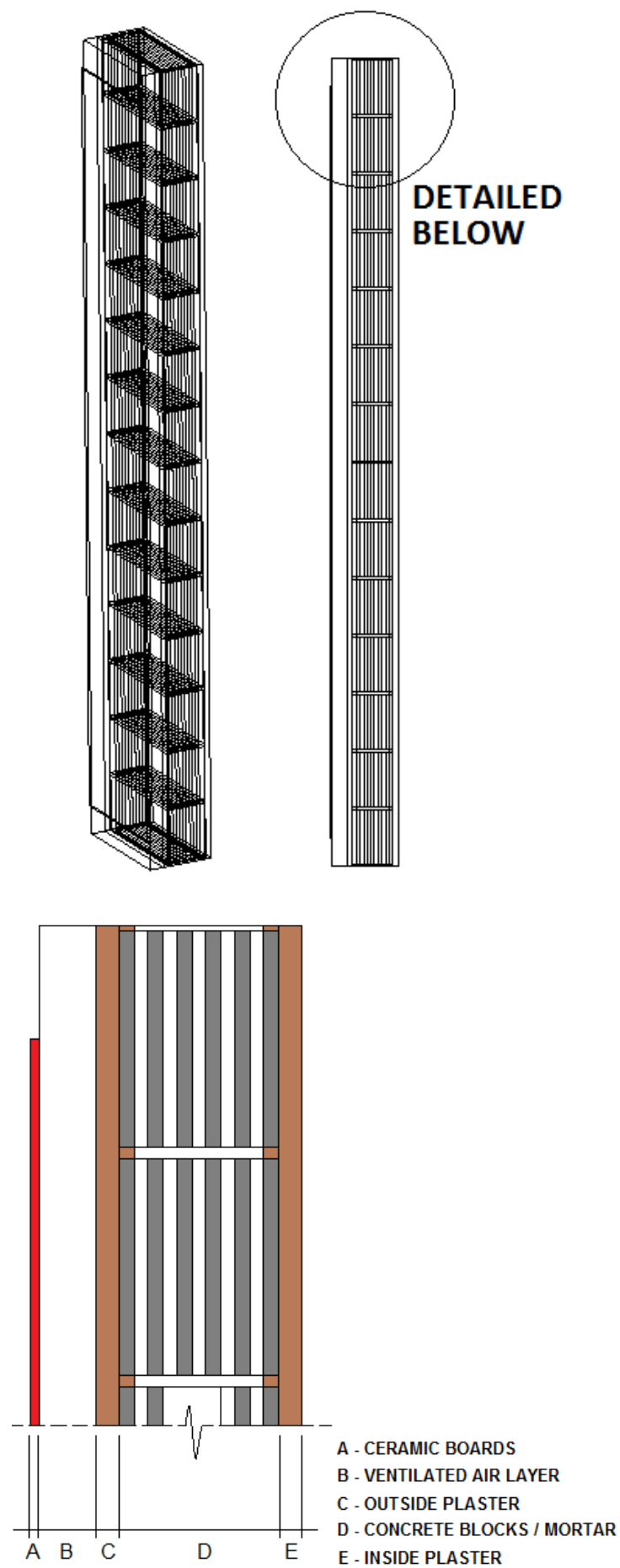

Fig. 11. Simulated Domains.

According to the analysis of the temperature fields, the air flow rate from the ventilated air layer removes the heat from the direct radiation in the outdoor environment efficiently and can avoid overheating of the wall, 
maintaining the inner surface temperature. The airflow generated inside the air layer upwards is intense reaching a mean velocity of around $0.5 \mathrm{~m} / \mathrm{s}$. Its convective heat transfer coefficient is approximately $16.0 \mathrm{~W}\left(\mathrm{~m}^{2} \mathrm{~K}\right)-1$.

Therefore, the installation of the ventilated air layer is effective, which can also be demonstrated when comparing the results of case \#2 and case \#3 when simulated with the BES-CFD coupling method. This effect can be analysed in Figure 13.

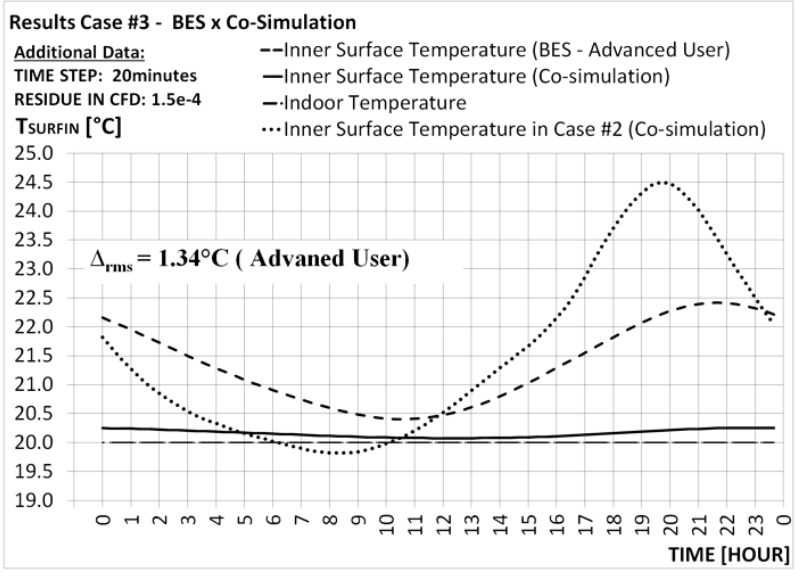

Fig. 12. Results Case \#3: mean inner surface temperature.

Table 3. Case \#3 - Quantity of exchanged energy for both simulation methods - Traditional vs. Co-simulation.

\begin{tabular}{|c|c|c|}
\hline Energy & $\begin{array}{c}\mathrm{E}_{\mathrm{T}_{\_} \text {out }} \\
(\mathrm{kJ})\end{array}$ & $\begin{array}{c}\mathrm{E}_{\mathrm{T} \_ \text {in }} \\
(\mathrm{kJ})\end{array}$ \\
\hline Advanced BES User (2) & 0 & 22,248 \\
\hline Co-simulation BES-CFD (3) & -646 & 2,645 \\
\hline Difference (\%) (2-3) & - & $-88 \%$ \\
\hline
\end{tabular}

Therefore, despite the high computational cost, the BES-CFD coupling method becomes a powerful tool for the analysis of ventilated air layers. The ventilated air cavity, usually built to shield against the moisture from the rain and solar radiation, mitigates the influences of these phenomena on the inner surface of the wall. However, as reported in [27], the authors in the literature have not reached a consensus about the efficacy of the installation of a ventilated air layer. Specific characteristics of the climate conditions of each location and building characteristics of the air cavity could result in an unfavourable performance. Therefore, future simulations may investigate the efficacy of installations in buildings, study the effect of alterations of their design characteristics and also, for instance, evaluate the changes in the performance of the air gap due to the influences of channelled winds.

Table 4 below summarizes the results of cases 1, 2 and 3 , which evaluated the gains in the precision of the results with the approach that details the inside the wall, provided by the coupling of software. Overall, the users of the Building Energy Simulation software still have to deal with a large number of errors.

Table 5 brings the equivalent thermal conductivity of the concrete block and mortar set used by each user in three cases.

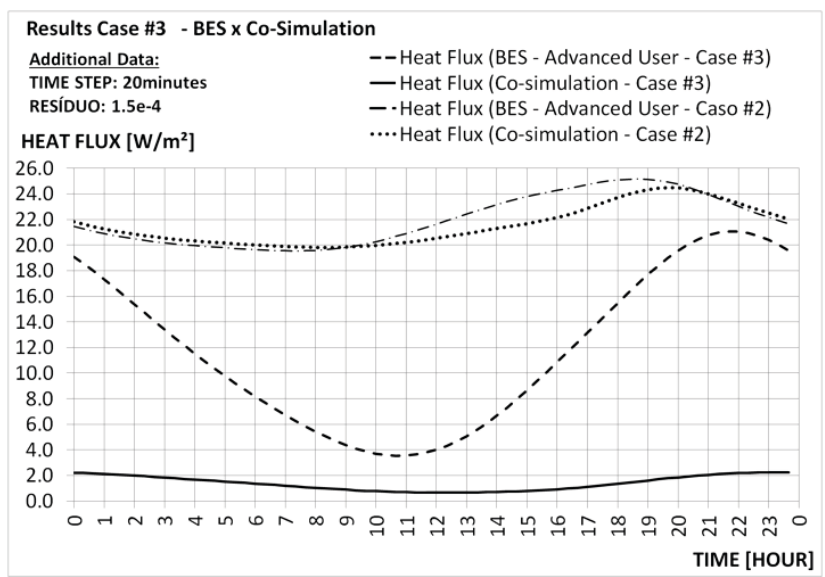

Fig. 13. Results Case \#3: heat flux at the inner surface.

Table 4. Abstract of results found on Cases \#1, \#2, and \#3.

\begin{tabular}{|c|c|c|c|c|}
\hline $\begin{array}{l}\text { Case } \\
\text { Study }\end{array}$ & Parameter & $\begin{array}{c}\text { Domus } \\
\text { Less } \\
\text { experienced } \\
\text { user }\end{array}$ & $\begin{array}{c}\text { Domus } \\
\text { Advanced } \\
\text { User }\end{array}$ & $\begin{array}{c}\underline{\text { BES- }} \\
\underline{\text { CFD }} \\
\text { Coupling }\end{array}$ \\
\hline \multirow{4}{*}{$\underline{\text { Case } 1}$} & \multirow{2}{*}{$\mathrm{T}_{\text {up_in }}$} & 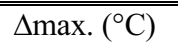 & $1.08 * *$ & $0.59^{\mathrm{R}}$ \\
\hline & & $\Delta_{\mathrm{rms}}\left({ }^{\circ} \mathrm{C}\right)$ & $0.62 * *$ & $0.36^{\mathrm{R}}$ \\
\hline & $\mathrm{E}_{\mathrm{T} \_ \text {out }}(\mathrm{kJ})$ & $\begin{array}{c}-13,399 * * \\
(-20.9 \%)\end{array}$ & $\begin{array}{l}-19,203 \\
(13.3 \%)\end{array}$ & $-16,947$ \\
\hline & $\mathrm{E}_{\mathrm{T} \_ \text {in }}(\mathrm{kJ})$ & $\begin{array}{c}986 * * \\
(-39.6 \%)\end{array}$ & $\begin{array}{c}2,326 \\
(42.4 \%)\end{array}$ & 1,633 \\
\hline \multirow{4}{*}{$\underline{\text { Case } 2}$} & \multirow{2}{*}{$\mathrm{T}_{\text {up_in }}$} & $\Delta \max .\left({ }^{\circ} \mathrm{C}\right)$ & $1.60 *$ & $2.15^{\mathrm{R}}$ \\
\hline & & $\Delta_{\mathrm{rms}}\left({ }^{\circ} \mathrm{C}\right)$ & $0.78 *$ & $1.00^{\mathrm{R}}$ \\
\hline & $\mathrm{E}_{\mathrm{T} \_ \text {out }}(\mathrm{kJ})$ & $\begin{array}{c}-198 * \\
(-38.7 \%)\end{array}$ & $\begin{array}{c}-1,142 \\
(253.6 \%)\end{array}$ & -323 \\
\hline & $\mathrm{E}_{\mathrm{T} \_ \text {in }}(\mathrm{kJ})$ & $\begin{array}{l}20,346 * \\
(-20.3 \%)\end{array}$ & $\begin{array}{c}33,616 \\
(31.8 \%)\end{array}$ & 25,513 \\
\hline \multirow{4}{*}{$\underline{\text { Case } 3}$} & \multirow{2}{*}{$\mathrm{T}_{\text {up_in }}$} & $\Delta \max .\left({ }^{\circ} \mathrm{C}\right)$ & - & $2.45^{\mathrm{R}}$ \\
\hline & & $\Delta_{\text {rms }}\left({ }^{\circ} \mathrm{C}\right)$ & - & $1.34^{\mathrm{R}}$ \\
\hline & $\mathrm{E}_{\mathrm{T}_{-} \text {out }}(\mathrm{kJ})$ & - & $\begin{array}{c}0 \\
(-100 \%)\end{array}$ & -646 \\
\hline & $\mathrm{E}_{\mathrm{T} \_ \text {in }}(\mathrm{kJ})$ & - & $\begin{array}{l}22,248 \\
(741 \%)\end{array}$ & 2,645 \\
\hline $\begin{array}{l}* \\
* * \\
\mathrm{R}\end{array}$ & $\begin{array}{l}\text { ic User } \\
\text { vanced User } \\
\text { erence value }\end{array}$ & & & \\
\hline
\end{tabular}


Table 5. Equivalent Conductivity used in Cases \#1, \#2, and \#3.

\begin{tabular}{|c|c|c|c|}
\hline $\begin{array}{l}\text { Case } \\
\text { Study }\end{array}$ & $\begin{array}{c}\frac{\mathrm{BES}}{\text { Basic User }} \\
{\left[\mathrm{W}(\mathrm{mK})^{-1}\right]}\end{array}$ & $\begin{array}{c}\underline{B E S} \\
\text { Prof. User } \\
{\left[\mathrm{W}(\mathrm{mK})^{-1}\right]}\end{array}$ & 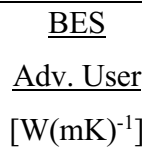 \\
\hline $\begin{array}{l}\text { Case } 1 \\
\end{array}$ & - & 0.304 & 0.498 \\
\hline Case 2 & 0.461 & - & 0.906 \\
\hline Case 3 & - & - & 0.498 \\
\hline
\end{tabular}

\section{Conclusions}

The present paper presented a novel approach for taking into account the 3-D heat transfer through complex building envelopes by coupling via co-simulation a BES software (Domus) with a CFD software (ANSYS CFX). The results of the new methodology were compared with those of the traditional 1-D approach and very expressive differences were found in terms of the inner surface temperature of the wall and the energy exchanged between indoor and outdoor environments. The following benefits can be listed:

i) A more realistic analysis of the heat transfer and fluid mechanics phenomena within the wall even for complex geometries;

ii) The precision by the high capability of detailing three-dimensionally the building envelope, including cavities, thermal bridges, anisotropic materials, trombe walls, joints, heat sources, which may significantly affect the building energy performance;

iii) The possibility of using the bi-dimensionality of information regarding radiative and convective boundary conditions;

iv) Accurate design of complex and highly energy efficient building elements, including the thermal mass effects thanks to the unsteady coupled approach.;

The present methodology has the potential to considerably increase the precision in the energy analysis of buildings or building elements. However, each application has its particularities and the gains in precision that can be offered by the 3-D analysis vary for each case, but the BES-CFD coupling method guarantees greater quality and precision to the user when compared to the BES software with the 1-D approach of the wall.

Due to the high computer run time with the CFD coupling, in the four study cases presented, only one wall was modelled, while the others were considered adiabatic. The existence of one single non-adiabatic wall reduces the interference of the external climatic conditions on the temperature of the indoor environment. Therefore, it is believed that the results would be more expressive if all walls were participating in the heat exchange between the indoor and outdoor environments.

Furthermore, the fact that the simulations provided the energy balance of the environment with the mean temperature of the inner surface of the wall, owing to the lack of a three-dimensional grid in the indoor environment, decreases the precision of the results, as the two-dimensional information on the wall surface obtained by the CFD software is lost.

Therefore, the carried out simulations presented promising results that motivate the continuation of the development, including CFD analysis in the indoor and outdoor environments by using advance co-simulation approaches as recently presented in [28-29].

The authors acknowledge the Brazilian agencies CAPES, of the Ministry of Education, and $\mathrm{CNPq}$, of the Ministry of Science, Technology and Innovation, for the financial support. The authors also acknowledge the iESSS (ESSS Institute for Education, Research and Development) and ANSYS for the technical and research support. This work emerged from the Annex 60 project, an international project conducted under the umbrella of the International Energy Agency (IEA) within the Energy in Buildings and Communities (EBC) Programme. Annex 60 developed and demonstrated new generation computational tools for building and community energy systems based on Modelica, Functional Mock-up Interface and BIM standards.

\section{References}

1. U.S. Energy Information Administration. Annual Energy Outlook 2015, with projections to 2040. EIA, Washington, 2015

2. Crawley, D.B. and Hand, J. and Kummert, M. and Griffith, B.T. (2008) Contrasting the capabilities of building energy performance simulation programs. Building and Environment, 43 (4). pp. 661-673. ISSN 0360-1323

3. Mendes, M. Chhay, J. Berger, and D. Dutykh. Numerical methods for diffusion phenomena in building physics. PUC Press, Curitiba, 2016.

4. M.Woloszyn and C. Rode. Tools for performance simulation of heat, air and moisture conditions of whole buildings. Building Simulation, 1(1):5-24, 2008.

5. N. Aste, A. Angelotti, and M. Buzzetti. The influence of the external walls thermal inertia on the energy performance of well insulated buildings. Energy and Buildings, 41(11):1181 - 1187, 2009. 1

6. R. A. Taylor and M. Miner. A metric for characterizing the effectiveness of thermal mass in building materials.Applied Energy, 128(Supplement C):156 - 163, 2014.

7. K.J. Kontoleon, T.G. Theodosiou, and K.G. Tsikaloudaki. The influence of concrete density and conductivity on walls' thermal inertia parameters under a variety of masonry and insulation placements. Applied Energy, 112:325 - 337, 2013.

8. I. Axaopoulos, P. Axaopoulos, and Gelegenis J. Optimum insulation thickness for external walls on different orientations considering the speed and direction of the wind. Applied Energy, 117:167 $175,2014$. 
9. M. Ozel. Effect of wall orientation on the optimum insulation thickness by using a dynamic method. Applied Energy, 88(7):2429 - 2435, 2011.

10. S. Al-Sanea, M.F. Zedan, and S. Al-Ajlan. Effect of electricity tariff on the optimum insulation-thickness in building walls as determined by a dynamic heattransfer model. Applied Energy, 82(4):313 - 330, 2005.

11. M. Ibrahim, P.H. Biwole, P. Achard, E.Wurtz, and G. Ansart. Building envelope with a new aerogelbased insulating rendering: Experimental and numerical study, cost analysis, and thickness optimization. Applied Energy, 159:490 - 501, 2015.

12. D.E.M. Bond, W.W. Clark, and M. Kimber. Configuring wall layers for improved insulation performance. Applied Energy, 112:235 - 245, 2013.

13. S.A. Al-Sanea and M.F. Zedan. Improving thermal performance of building walls by optimizing insulation layer distribution and thickness for same thermal mass. Applied Energy, 88(9):3113 - 3124, 2011.

14. Negrão, C.; Integration of computational fluid dynamics with building thermal and mass flow simulation. Energy and Buildings, v. 27, pp. 155165, 1998.

15. Zhai Z., Chen Q.; Strategies for coupling energy simulation and computational fluid dynamics programs. Lawrence Berkeley National Laboratory, 2001.

16. Zhai Z., Chen Q.; Solution characters of iterative coupling between energy simulation and CFD programs. Energy and Buildings, v.35, pp. 493-505, 2003.

17. Zhai Z., Chen Q.; Numerical determination and treatment of convective heat transfer coefficient in the coupled building energy and CFD simulation. Building and Environment, v.39, pp. 1001-1009, 2004.

18. Zhai Z., Chen Q.; Sensitivity analysis and application guides for integrates building energy and CFD simulation. Energy and Buildings, v.38, pp. 1060-1068, 2006.

19. Bartak M.; Beausoleil-Morrison I.; Clarke J.A.; Denev J.; Drkal F.; Lain M.; Macdonald I.A.; Melikov A.; Popiolek Z.; Stankov P.; Integrating CFD and building simulation. Building and Environment, v.37, pp.865-871, 2002.

20. Djunaedy E.; Hensen J.L.M.; Loomans M.G.L.C.; External Coupling between CFD and Energy Simulation: Implementation and Validation. ASHRAE Transactions, v.111, Part 1, 2005.

21. Wang L.; Wong N.H.; Coupled simulations for naturally ventilated rooms between building simulation (BS) and computational fluid dynamics (CFD) for better prediction of indoor thermal environment. Building and Environment, v.44, pp.95-112, 2009.
22. Cherem Pereira G.; Bloco de concreto: aprimoramento e análise avançada de desempenho térmico. Doctoral Thesis, Mechanical Engineering Graduate Program, Pontifical Catholic University of Parana, 2017.

23. Hagentoft C. E.; Hamstad WP2; Modeling; v.4 Chalmers University of technology, Department of Building Physics, p 1-17, 2001.

24. Rocha A.P., Oliveira R.C.L.F., Mendes N.; Experimental validation and comparison of direct solar shading calculations within building energy simulation tools: polygon clipping and pixel counting techniques. Solar Energy, 2017,

25. NBR 15220 - Desempenho Térmico de Edificações; ABNT - Brazilian Association of Technical Standards, 2003.

26. ISO 6946:1996(E) - Building componentes and building elements - Thermal resistance and termal transmittance - Calculation method. 1996.

27. Belleguem, M. V.; Steeman, M.; Janssens A.; Paepe M.; Heat, air and moisture transport modelling in ventilated cavity walls. Journal of Building Physics, Vol. 38(4), p. 317-349, 2014.

28. Mazuroski W., Berger J., Mendes N., Oliveira R. C.L.F.; An artificial intelligence-based method to efficiently bring CFD to building simulation. Journal of Building Performance Simulation, 2017, doi:10.1080/19401493.2017.1414880.

29. Berger J., Mazuroski W., Mendes N., Oliveira R. C.L.F.; Intelligent co-simulation: neural network vs. proper orthogonal decomposition applied to a $2 D$ diffusive problem. Journal of Building Performance Simulation,2017,doi:10.1080/19401493.2017.14148 79. 